\title{
DAMPAK TEKNIK PENYULUHAN FOCUS GROUP DISCUSSION (FGD) TERHADAP PERUBAHAN PENGETAHUAN, SIKAP DAN PENERAPAN PADA PENYULUH DAN PETERNAK SAPI BALI DI BALI
}

\author{
DWIWATI, D. M1), N. SUPARTA ${ }^{2)}$, DAN I G. S. A. PUTRA ${ }^{1)}$ \\ 1) Mahasiswa Program Studi Magister Ilmu Peternakan, Universitas Udayana \\ 2) Fakultas Peternakan Universitas Udayana, Denpasar Bali \\ e-mail: dayudwi61@yahoo.com
}

\begin{abstract}
ABSTRAK
Penyuluhan diharapkan dapat menghasilkan perubahan perilaku menjadi lebih baik. Ada banyak metode yang dilakukan dalam menyelenggarakan penyuluhan, namun tingkat keefektifannya bervariasi. Untuk itu perlu dicoba menggunakan teknik FGD yang dapat melibatkan partisipasi sasaran secara lebih baik. Tujuan penelitian ini adalah (1) mendeskripsikan teknik FGD dalam proses penyuluhan (2) mengetahui dampak FGD terhadap perubahan pengetahuan, sikap dan penerapan penyuluh di Bali (3) mengetahui dampak FGD terhadap perubahan pengetahuan, sikap dan penerapan peternak sapi bali di Bali. Penelitian dilaksanakan di wilayah Kecamatan Penebel Kabupaten Tabanan, Kecamatan Kintamani Barat Kabupaten Bangli dan Kecamatan Gerokgak Kabupaten Buleleng. Penelitian dirancang sebagai penelitian quasi experimental. Sampel diambil secara quota stratified random sampling. Dipilih 10 orang penyuluh dan 50 orang peternak dari masing-masing kecamatan, sehingga total responden adalah 30 orang penyuluh dan 150 orang peternak. Hasil penelitian menunjukkan bahwa teknik FGD efektif digunakan dalam proses penyuluhan peternakan, teknik FGD berdampak positif dan memiliki hubungan yang signifikan terhadap perubahan pengetahuan, sikap, dan penerapan pada penyuluh maupun peternak sapi bali di Bali. FGD dapat dianjurkan untuk digunakan sebagai salah satu alternatif metode penyuluhan, terutama dalam upaya lebih mengaktifkan partisipasi peternak sasaran.
\end{abstract}

Kata kunci: metode penyuluhan FGD, pengetahuan, sikap, penerapan

\section{IMPACT OF COUNSELING TECHNIQUES FOCUS GROUP DISCUSSION (FGD) TO CHANGES OF KNOWLEDGE, ATTITUDE AND APPLICATION OF INSTRUCTOR AND BALI CATTLE BREEDER IN BALI}

\begin{abstract}
Extension is expected to get the best behavioral changes. There are many methods conducted in organizing counseling, but the level of effectiveness varies. It is necessary to try to use FGD techniques that involve the participation of target better. The purpose of this study were (1) describe the FGD techniques in the process of extension (2) determine the impact of FGD on changes in knowledge, attitude and application of the extension in Bali (3) determine the impact of FGD on changes in knowledge, attitude and application of bali cattle farmers in Bali. The experiment was conducted in the Penebel Tabanan District, West Kintamani Bangli District and Gerokgak Buleleng District. The study was designed as a quasi-experimental study. Samples taken by quota stratified random sampling. Selected 10 counselors and 50 farmers from each district, so the total respondents were 30 counselors and 150 breeders. The results showed that effective FGD techniques used in the process of farm extension, Engineering FGD positive impact and has a significant relationship to changes in knowledge, attitudes, and application, extension workers and farmers in Bali Bali cattle.
\end{abstract}

Key words: counseling methods, FGD, knowledge, attitude, application 


\section{PENDAHULUAN}

Pertanian merupakan sektor penting di Indonesia karena sebagian besar penduduk masih bermata pencaharian di sektor pertanian, serta menjadi penyedia kebutuhan pangan yang semakin meningkat. Sektor pertanian diharapkan mampu untuk: (1) berswasembada, (2) berdiversifikasi pangan (3), berdaya saing, dan ekspor, serta (4) meningkatkan kesejahteraan petani (RKT Kementerian Pertanian 2010). Untuk mewujudkannya, maka diperlukan upaya pengembangan dengan cara mengadopsi berbagai teknologi tepat guna. Subsektor peternakan merupakan bagian yang memiliki peranan penting dalam menopang perekonomian masyarakat.

Fakta empiris menunjukkan bahwa adopsi teknologi pertanian belum sesuai harapan. Hal ini sejalan dengan Wiguna (2013) menyatakan bahwa masih rendahnya dukungan penyuluhan pertanian di Bali. Permasalahan lain yang dialami oleh peternak adalah petani belum mampu mengatasi permasalahan di dalam kelompoknya.

Penyuluhan pertanian kurang berpengaruh terhadap perilaku petani dalam mengadopsi teknologi baru, walaupun inovasi yang diperkenalkan merupakan modifikasi teknologi yang telah ada dan telah diujicobakan. Peternak masih berpegang pada teknologi lokal. Kenyataan tersebut terjadi, karena latar belakang pendidikan, tradisi atau budaya serta karakter pada peternak. Diperlukan upaya untuk mengefektifkan penyuluhan dengan tetap memperhatikan fungsi, teknik atau metode, tujuan dan sasaran penyuluhan.

Penerapan metode penyuluhan seperti Focus Group Discussion (FGD) diharapkan mampu mengatasi permasalahan yang ada. Menurut Henning dan Coloumbia (1990), Focus Group Discussion (FGD) atau diskusi kelompok terarah adalah diskusi dari sekelompok kecil orang yang dipimpin oleh seorang moderator yang secara halus mendorong peserta untuk berani berbicara terbuka dan spontan.

Penggunanaan metode FGD karena: (1) adanya keyakinan bahwa masalah yang diteliti tidak dapat dipahami dengan metode survei atau wawancara, (2) agar memperoleh data kualitatif yang bermutu dengan lebih cepat, (3) cocok bagi permasalahan yang bersifat sangat lokal spesifik, dan (4) menumbuhkan peranan memilih dari masyarakat yang diteliti, sehingga peneliti dapat memberikan rekomendasi dengan mudah dan masyarakat mau menerima rekomendasi tersebut.

\section{MATERI DAN METODE}

\section{Lokasi dan Waktu Penelitian}

Penelitian ini dilakukan pada tiga kecamatan dari tiga kabupaten yang mempunyai populasi ternak sapi bali terbanyak di Bali, yakni Kecamatan Penebel Ka- bupaten Tabanan, Kecamatan Kintamani Barat Kabupaten Bangli, dan Kecamatan Gerokgak Kabupaten Buleleng. Pemilihan lokasi ditentukan dengan menggunakan metode purposive sampling, yaitu suatu metode penentuan daerah penelitian yang didasarkan atas pertimbangan-pertimbangan tertentu (Hadi, 1999). Dasar pertimbangannya adalah pada tiga kecamatan dari tiga kabupaten tersebut, sebagian besar warganya memelihara ternak sapi bali, mata pencaharian utamanya masih di sektor pertanian, sudah menjadi anggota kelompok tani-ternak dan dibina oleh penyuluh, serta lokasi sudah dikenal dan mudah dicapai dengan sarana transportasi yang ada.

Penelitian lapangan dilakukan selama 2 (dua) bulan yaitu bulan September sampai dengan Oktober 2015.

\section{Rancangan Penelitian}

Penelitian dirancang sebagai penelitian quasi experimental design (Faisal, 1999) yaitu teknik FGD ditetapkan sebagai metode penyuluhan baik pada penyuluh maupun peternaknya.

\section{Populasi dan Sampel}

Populasi penelitian adalah semua penyuluh pertanian dan peternak sapi bali di Bali. Penentuan sampel dalam penelitian ini dilakukan secara quota stratified random sampling, dimana responden penyuluh ditentukan dengan cara mengambil 10 orang penyuluh yang berperan dalam melakukan penyuluhan di kecamatan terpilih yang dijadikan lokasi penelitian dengan stratifikasi adalah penyuluh pertanian yang mempunyai wilayah kerja dan membina kelompok tani atau kelompok ternak sapi. Selanjutnya dari 10 orang penyuluh yang sudah di FGD ditentukan lagi 5 orang berdasarkan jumlah kelompok binaan di wilayah kerjanya, selanjutnya masing-masing penyuluh menentukan 10 orang peternak berdasarkan stratifikasi adalah peternak sapi bali dan dalam wadah kelompok tani maupun kelompok ternak. Dengan demikian, total responden penyuluh sebanyak 30 orang dan responden peternak sapi bali sebanyak 150 orang.

\section{Sumber Data dan Teknik Pengumpulan Data}

Data yang dikumpulkan dalam penelitian ini terdiri atas data primer dan data sekunder. Data primer adalah data yang didapat langsung dari responden (penyuluh dan peternak sapi bali). Jenis data terdiri atas data kuantitatif dan kualitatif. Data kuantitatif adalah data kualitatif yang diangkakan melalui teknik scoring. Sedangkan, data sekunder adalah data yang diperoleh melalui catatan-catatan atau laporan yang ada di BPP setempat dan Dinas Peternakan atau sumber lain yang dapat dipercaya.

Pengumpulan data dilakukan dengan cara wawa- 
ncara langsung, menggunakan kuesioner terstruktur (Singarimbun dan Effendi, 1995), observasi langsung ke lokasi untuk mengetahui kondisi objek penelitian agar memperoleh informasi yang lebih jelas, serta metode dokumentasi yakni merekam catatan-catatan yang ada pada kelompok, Dinas Peternakan, dan lainnya.

\section{Instrumen Penelitian}

Data primer diperoleh melalui diskusi langsung dalam FGD, serta kuisioner yang telah dipersiapkan, alat perekam seperti kamera foto dan catatan. Kuisioner untuk peternak terdiri dari pertanyaan mengenai identitas, pengetahuan, sikap dan penerapan mengenai kegiatan penyuluhan, pelayanan, dan pengaturan yang merupakan kebijakan pemerintah. Kuisioner untuk penyuluh berupa pertanyaan-pertanyaan mengenai identitas, pengetahuan, sikap dan penerapan penyuluh mengenai kegiatan penyuluhan, pelayanan, dan pengaturan yang merupakan kebijakan pemerintah. serta kegiatan penyuluhan yang dilakukan oleh penyuluh dalam beternak sapi bali.

\section{Variabel Penelitian}

Variabel yang diamati dalam penelitian ini adalah teknik FGD, perubahan pengetahuan, sikap, dan penerapan pada penyuluh maupun pada peternak sapi bali.

\section{Analisis Data}

Data responden dianalisis secara deskriptif. Hasildata mendeskripsikan tentang peningkatan pengetahuan, sikap dan penerapan sebelum dan sesudah dilaksanakan FGD. Analisis perubahan pengetahuan, sikap dan penerapan penyuluh antara sebelum dan sesudah FGD serta perubahan pengetahuan, sikap dan penerapan peternak antara sebelum dan sesudah FGD, digunakan uji $\mathrm{t}$ - test. Jika terjadi perbedaan pengetahuan, sikap, dan penerapan pada penyuluh maupun pada peternak antara sebelum dan sesudah dilakukan FGD lebih kecil dari 5\% $(\mathrm{P}<\mathrm{O}, 05)$ maka dinyatakan meningkat secara signifikan. Artinya teknik FGD dapat diterapkan sebagai salah satu metode yang efektif.

\section{HASIL DAN PEMBAHASAN}

\section{Pelaksanaan FGD}

Pelaksanaan FGD dalam penelitian ini sangat direspon oleh peserta (penyuluh dan peternak), karena teknik FGD merupakan teknik yang baru pertama kali mereka dapatkan. Peserta mengalami dan memahami bahwa interaksi antar peserta merupakan dasar untuk memperoleh informasi, peserta mempunyai kesempatan yang sama untuk mengajukan dan memberikan pernyataan, menanggapi, maupun mengajukan pertanyaan.
Dalam pelaksnaan FGD baik di tingkat penyuluh maupun peternak, terlebih dahulu dilakukan pre-tes, setelah itu dilanjutkan dengan FGD dan akhir kegiatan dilakukan post-tes. Selama pelaksanaan, penyuluh maupun peternak terlibat langsung dalam suasana diskusi yang terarah dan dipandu oleh seorang moderator. Narasumber yang hadir pada saat pelaksanaan FGD adalah dari BPTP Bali, Dinas Peternakan dan Kesehatan Hewan Provinsi Bali dan Akademisi Universitas Udayana.

\section{Perilaku penyuluh}

Hasil penelitian menunjukkan bahwa pengetahuan penyuluh sebelum FGD 40,54\%, dan sesudah FGD $65,94 \%$. Terjadi peningkatan cukup tinggi 25,40 $(62,64 \%)$. Indikator pengetahuan tertinggi peningkatannya adalah pemilihan bakalan $144,71 \%$, dan menduga umur sapi 109,52\%. Hal ini disebabkan karena kedua indikator itu memang dianggap penting untuk dipahami oleh penyuluh, sehingga tinggi perhatiannya dan untuk lebih jauh memahaminya. Indikator yang terendah peningkatannya adalah pakan 10,67 (17,68\%), seperti pada Tabel 1.

Faktor lain yang berpengaruh adalah latar belakang pendidikan, umur dan masa kerja menjadi penyuluh. Hal ini sesuai dengan pendapat Mosher (1987) yang menyatakan semakin tinggi tingkat pendidikan formal yang dialami oleh seseorang, maka tingkat pengetahuan, ketrampilan serta sikapnya lebih terbuka terhadap teknologi baru. Demikian juga masa kerja penyuluh yang cukup lama, sehingga penyuluh lebih meningkatkan pengetahuannnya untuk belajar dan mencari informasi yang lebih lengkap.

\begin{tabular}{|c|c|c|c|c|c|}
\hline \multirow{3}{*}{\multicolumn{2}{|c|}{$\begin{array}{l}\text { Indikator Teknis dan Manajemen } \\
\text { Beternak Sapi Bali }\end{array}$}} & \multicolumn{4}{|c|}{ Pengetahuan penyuluh } \\
\hline & & \multirow{2}{*}{$\begin{array}{l}\text { Sebelum } \\
\text { FGD (\%) }\end{array}$} & \multirow{2}{*}{$\begin{array}{l}\text { Sesudah } \\
\text { FGD (\%) }\end{array}$} & \multicolumn{2}{|c|}{ Peningkatan } \\
\hline & & & & Satuan & (\%) \\
\hline 1 & Mengenal ciri-ciri sapi bali & 44,00 & 75,67 & 31,67 & 71,97 \\
\hline 2 & Menduga umur sapi & 21,00 & 44,00 & 23,00 & 109,52 \\
\hline 3 & Keunggulan sapi bali & 38,00 & 75,33 & 37,33 & 98,25 \\
\hline 4 & Memilih bakalan & 28,33 & 69,33 & 41,00 & 144,71 \\
\hline 5 & Kandang & 49,67 & 72,67 & 23,00 & 46,31 \\
\hline 6 & Pakan & 60,33 & 71,00 & 10,67 & 17,68 \\
\hline 7 & Perkawinan & 45,67 & 58,17 & 12,50 & 27,37 \\
\hline 8 & Penyakit & 37,33 & 61,33 & 24,00 & 64,29 \\
\hline & Total & 324,33 & 527,50 & 203,17 & 580,09 \\
\hline & Rataan & 40,54 & 65,94 & 25,40 & 62,64 \\
\hline
\end{tabular}

Sikap penyuluh meningkat yakni 31,67 (54,05\%). Nilai tertinggi peningkatannya adalah teknologi IB 40,67 $(76,25 \%)$, dan kerjasama penumbuhan kelembagaan 37,67 (72,90\%). Indikator sikap tertinggi sebelum FGD 
adalah integrasi tanaman pakan dan ternak $63,33 \%$ dan sesudah FGD sikap tertinggi adalah teknologi IB (94\%), seperti pada Tabel 2.

Tingkat penguasaan materi penyuluhan sangat mempengaruhi sikap penyuluh, karena sikap seseorang akan menentukan langkah selanjutnya yaitu penerapan inovasi. Setelah dilaksanakan FGD, terjadi peningkatan perubahan sikap, karena penyuluh memahami betul permasalahan yang dihadapi di lapangan berkaitan dengan usaha peternaknya.

Kondisi wilayah dan kebiasaan yang sudah turun menurun akan mempengaruhi sulitnya perubahan sikap seseorang. Terlebih bila teknologi yang akan diterima belum sepenuhnya dipahami oleh penyuluh. Walgito (2003) berpendapat bahwa sikap merupakan organisasi pendapat, keyakinan seseorang mengenai obyek, yang disertai adanya perasaan tertentu dan memberikan dasar kepada orang tersebut untuk membuat respon atau berperilaku dalam cara tertentu yang dipilihnya.

Faktor lain yang mempengaruhi pembentukan dan perubahan sikap adalah pengalaman pribadi, kebudayaan orang lain yang dianggap penting, media massa, lembaga pendidikan serta faktor emosi dalam diri individu. Sikap yang ada pada diri seseorang akan dipengaruhi oleh faktor internal (faktor fisiologis dan psikologis) serta faktor eksternal dapat berwujud situasi yang dihadapi oleh individu, norma-norma yang ada dalam masyarakat (Walgito, 2003).

Tabel 2. Sikap Penyuluh Tentang Teknis dan Manajemen Beternak Sapi Bali di Bali Sebelum dan Sesudah FGD

\begin{tabular}{|c|c|c|c|c|c|}
\hline \multirow{3}{*}{\multicolumn{2}{|c|}{$\begin{array}{c}\text { Indikator Teknis dan Manajemen } \\
\text { Beternak Sapi Bali }\end{array}$}} & \multicolumn{4}{|c|}{ Sikap penyuluh } \\
\hline & & \multirow{2}{*}{\multicolumn{2}{|c|}{$\begin{array}{l}\text { Sebelum Sesudah } \\
\text { FGD (\%) FGD (\%) }\end{array}$}} & \multicolumn{2}{|c|}{ Peningkatan } \\
\hline & & & & Satuan & (\%) \\
\hline 1 & Tugas menyuluh tentang sapi bali & 61,00 & 89,67 & 28,67 & 46,99 \\
\hline 2 & $\begin{array}{l}\text { Integrasi tanaman pangan dan } \\
\text { ternak }\end{array}$ & 63,33 & 92,00 & 28,67 & 45,26 \\
\hline 3 & $\begin{array}{l}\text { Kemampuan memelihara sapi } \\
\text { sesuai potensi }\end{array}$ & 61,67 & 87,00 & 25,33 & 41,08 \\
\hline 4 & $\begin{array}{l}\text { Inovasi pengolahan limbah dan } \\
\text { pakan ternak }\end{array}$ & 62,33 & 91,67 & 29,33 & 47,06 \\
\hline 5 & $\begin{array}{l}\text { Penyelamatan betina produktif, } \\
\text { penguatan wilayah sumber bibit } \\
\text { dan usaha pembibitan }\end{array}$ & 57,67 & 92,00 & 34,33 & 59,54 \\
\hline 6 & $\begin{array}{l}\text { Penyediaan kredit dan distribusi } \\
\text { pemasaran }\end{array}$ & 57,67 & 86,33 & 28,67 & 49,71 \\
\hline 7 & Teknologi IB & 53,33 & 94,00 & 40,67 & 76,25 \\
\hline \multirow[t]{3}{*}{8} & $\begin{array}{l}\text { Kerjasama dan penumbuhan } \\
\text { kelembagaan }\end{array}$ & 51,67 & 89,33 & 37,67 & 72,90 \\
\hline & Total & 468,67 & 722,00 & 253,33 & 438,80 \\
\hline & Rataan & 58,58 & 90,25 & 31,67 & 54,05 \\
\hline
\end{tabular}

Penerapan penyuluh meningkat $16,46(20,88 \%)$ dari $78,83 \%$ menjadi $95,29 \%$. Tidak ada indikator penerapan yang meningkat tajam dan peningkatan tertinggi adalah indikator inovasi pakan hanya 22,00 (30,00\%).
Nilai indikator penerapan teknis dan manajemen beternak sapi yang tertinggi sebelum FGD adalah jadwal dan metode penyuluhan $(84,00)$ sesudah FGD adalah perencanaan dan pedoman penyuluhan $(97,00 \%)$, disajikan pada Tabel 3 .

Faktor yang berpengaruh pada peningkatan penerapan penyuluh adalah motivasi dan tanggung jawab kepada profesi pekerjaannya serta sikap yang positif. Masa kerja serta pengalaman selama menjadi penyuluh akan mencerminkan rasa tanggungjawab yang besar terhadap tugas dan fungsinya sebagai penyuluh. Penyuluh yang demikian akan mengiplementasikan dalam bentuk membuat rencana kerja tahunan dan rencana definitif kebutuhan kelompok, serta membuat pedoman dan menggunakan metode penyuluhan yang tepat sesuai sasaran penyuluhan. Mulyono Makmur (2007) menyatakan bahwa faktor syarat kerja dan faktor pendorong seorang penyuluh akan mempengaruhi dilaksanakannya pekerjaan dengan baik atau tidak.

Hasil analisis menunjukkan bahwa terjadi perubahan yang signifikan $(\mathrm{P}<0,05)$ pada perilaku penyuluh tentang teknis dan manajemen beternak sapi bali di Bali antara sebelum dan sesudah dilakukan FGD.

Tabel 3. Penerapan Penyuluh Tentang Teknis dan Manajemen Beternak Sapi Bali di Bali Sebelum dan Sesudah FGD

\begin{tabular}{lrrrr} 
Indikator Teknis dan Manajemen & \multicolumn{5}{c}{ Penerapan Penyuluh } \\
\multicolumn{1}{c}{ Beternak Sapi Bali } & Sebelum & Sesudah & Peningkatan \\
& FGD (\%) & FGD (\%) & Satuan & \multicolumn{1}{c}{$(\%)$} \\
1 Rencana Kerja dan RDKK & 76,33 & 94,67 & 18,33 & 24,02 \\
2 Jadwal dan metode penyuluhan & 84,00 & 95,67 & 11,67 & 13,89 \\
3 Perencanaan dan pedoman & 77,67 & 97,00 & 19,33 & 24,89 \\
$\quad$ penyuluhan & & & & \\
4 Keanggotaan kelompok & 79,67 & 95,67 & 16,00 & 20,08 \\
5 Inovasi teknologi pakan & 73,33 & 95,33 & 22,00 & 30,00 \\
6 Inovasi teknologi limbah & 78,67 & 95,33 & 16,67 & 21,19 \\
7 Pengendalian penyakit & 80,33 & 93,33 & 13,00 & 16,18 \\
8 Analisa Usaha Ternak & 80,67 & 95,33 & 14,67 & 18,18 \\
$\quad$ Total & 630,67 & 762,33 & 131,67 & 168,43 \\
$\quad$ Rataan & 78,83 & 95,29 & 16,46 & 20,88 \\
\hline
\end{tabular}

\section{Perilaku peternak}

Hampir semua indikator pengetahuan peternak meningkat tajam, yakni mengenal ciri-ciri sapi bali 26,67 (74,07\%), kandang 27,33 (67,77\%), dan perkawinan 28,00 (67,74\%), seperti pada Tabel 4. Hal ini membuktikan bahwa peternak sangat antusias mengikuti diskusi, banyak hal-hal yang muncul merupakan persoalan-persoalan aktual di lapangan. Diskusi yang terjadi membuat tidak mengantuk dan justru lebih mudah menangkapnya.

Hal ini menggambarkan bahwa peternak sapi bali, sebelumnya sudah tahu tetapi belum banyak memahami, karena teknik penyuluhan yang digunakan belum tepat, sehingga teknik FGD dianggap sebagai cara yang 
baik untuk menerima pengetahuan baru, dan mampu meningkatkan nilai pengetahuan peternak.

Tabel 4. Pengetahuan Peternak Tentang Teknis dan Manajemen Beternak Sapi di Bali Sebelum dan Sesudah FGD

\begin{tabular}{|c|c|c|c|c|}
\hline \multirow{3}{*}{$\begin{array}{l}\text { Indikator Teknis dan Manajemen } \\
\text { Beternak Sapi Bali }\end{array}$} & \multicolumn{4}{|c|}{ Pengetahuan Peternak } \\
\hline & \multirow{2}{*}{$\begin{array}{c}\text { Sebelum } \\
\text { FGD (\%) }\end{array}$} & \multirow{2}{*}{$\begin{array}{l}\text { Sesudah } \\
\text { FGD (\%) }\end{array}$} & \multicolumn{2}{|c|}{ Peningkatan } \\
\hline & & & Satuan & $(\%)$ \\
\hline 1 Mengenal ciri-ciri sapi bali & 36,00 & 62,67 & 26,67 & 74,07 \\
\hline 2 Menduga umur sapi & 42,33 & 70,67 & 28,33 & 66,93 \\
\hline 3 Keunggulan sapi bali & 45,00 & 74,33 & 29,33 & 65,19 \\
\hline 4 Memilih bakalan & 41,67 & 68,67 & 27,00 & 64,80 \\
\hline 5 Kandang & 40,33 & 67,67 & 27,33 & 67,77 \\
\hline 6 Pakan & 43,33 & 72,33 & 29,00 & 66,92 \\
\hline 7 Perkawinan & 41,33 & 69,33 & 28,00 & 67,74 \\
\hline 8 Penyakit & 49,00 & 73,00 & 24,00 & 48,98 \\
\hline Total & 339,00 & 558,67 & 219,67 & 522,40 \\
\hline Rataan & 42,38 & 69,83 & 27,46 & 64,80 \\
\hline
\end{tabular}

Peningkatan pengetahuan peternak tentang penyakit adalah terendah 24,00 (48,98\%), disajikan pada Tabel 4. Kenyataan di lapangan, pengetahuan peternak tentang penyakit diperoleh dari pengalaman selama beternak, jika terjadi gejala atau serangan penyakit pada ternaknya, maka peternak cukup menghubungi dokter hewan setempat. Dengan demikian, peternak menerima secara langsung penjelasan tentang gejala atau jenis penyakit yang sering menyerang ternak sapi. Sedangkan pengetahuan tentang keunggulan sapi bali diperoleh dari pengalaman dan selama melaksanakan FGD, dimana terjadi saling memberikan informasi sesama peserta sesuai pengalaman masing-masing peternak.

Umur mempengaruhi kemampuan fisik dan cara berpikir. Makin muda umurnya, mempunyai semangat untuk ingin tahu yang lebih tinggi, sehingga ada upaya untuk mengikuti penyuluhan-penyuluhan yang lebih sering dilakukan dalam kelompok dan lebih cepat melakukan adopsi inovasi. Semakin sering peternak mengikuti penyuluhan, maka pengetahuan peternak semakin meningkat. Setyarini (2009) menyatakan bahwa intensitas penyuluhan mempengaruhi pengambilan keputusan seseorang. Inggriati (2014) menyatakan bahwa, peternak yang memiliki pendidikan non formal lebih tinggi, akan memiliki kemampuan belajar lebih tinggi dan memiliki wawasan lebih luas

Rata-rata peningkatan nilai sikap peternak yakni 32,08(52,04\%),yaknidari62,33\% sebelum dilaksanakan FGD, menjadi 94,42\% setelah dilaksanakan FGD (Tabel 5). Hal ini disebabkan karena peternak sudah memahami inovasi dan dirasakan menguntungkan bagi usaha ternaknya, sehingga peternak akan bersikap positif untuk mencoba teknologi yang disuluhkan oleh penyuluh.

Sikap awal peternak rata-rata tinggi, seperti perencanaan berusaha ternak sapi (70\%), manajemen pe- meliharaan $65,67 \%$, tetapi peningkatannya tidak terlalu tinggi. Hal ini disebabkan karena peternak merasa perlu mengetahui, tetapi belum mampu menerapkan, sehingga sikapnya tidak terlalu banyak berubah. Sikap juga dipengaruhi oleh persepsi peternak tentang ciriciri inovasi dan perubahan yang dikehendaki. Hal ini mencerminkan bahwa sikap tidak dibawa seseorang sejak lahir, melainkan dibentuk sepanjang perkembangannya, sikap dapat berubah-ubah, oleh karena itu sikap dapat dipelajari.

Tabel 5. Sikap Peternak Tentang Teknis Dan Manajemen Beternak Sapi Bali di Bali Sebelum dan Sesudah FGD

\begin{tabular}{|c|c|c|c|c|c|}
\hline \multirow{3}{*}{\multicolumn{2}{|c|}{$\begin{array}{c}\text { Indikator Teknis dan Manajemen } \\
\text { Beternak Sapi Bali }\end{array}$}} & \multicolumn{4}{|c|}{ Sikap peternak } \\
\hline & & \multicolumn{2}{|c|}{ Sebelum Sesudah } & \multicolumn{2}{|c|}{ Peningkatan } \\
\hline & & FGD (\%) & FGD (\%) & Satuan & $(\%)$ \\
\hline 1 & Kegiatan penyuluhan budidaya sapi & 61,00 & 96,33 & 35,33 & 57,92 \\
\hline 2 & Perencanaan berusaha ternak sapi & 70,00 & 92,00 & 22,00 & 31,43 \\
\hline 3 & $\begin{array}{l}\text { Pemanfaatan sumberdaya } \\
\text { lingkungan }\end{array}$ & 61,67 & 97,00 & 35,33 & 57,30 \\
\hline 4 & Manajemen pemeliharaan & 65,67 & 91,67 & 26,00 & 39,59 \\
\hline \multirow{2}{*}{5} & Penyelamatan betina produktif dan & & & & \\
\hline & penguatan wilayah sumber bibit & 61,00 & 95,33 & 34,33 & 56,28 \\
\hline 6 & Penyediaan bibit melalui KUPS & 61,00 & 89,67 & 28,67 & 46,99 \\
\hline 7 & Kerjasama antar lembaga terkait & 60,00 & 97,33 & 37,33 & 62,22 \\
\hline \multirow[t]{3}{*}{8} & $\begin{array}{l}\text { Penumbuhan kelembagaan } \\
\text { peternak }\end{array}$ & 58,33 & 96,00 & 37,67 & 64,57 \\
\hline & Total & 498,67 & 755,33 & 256,67 & 416,32 \\
\hline & Rataan & 62,33 & 94,42 & 32,08 & 52,04 \\
\hline
\end{tabular}

Kemudahan dalam berinteraksi secara cepat dengan penyuluh dan intensitas kunjungan terhadap kelompok binaan juga akan mempengaruhi sikap peternak. Jika jumlah kelompok tani maupun kelompok ternak yang dibina oleh penyuluh terlalu banyak, apalagi satu penyuluh bisa membina dua wilayah binaan dengan jarak yang jauh, maka bisa dipastikan perubahan sikap peternak sulit untuk diubah. Suparta et al. (2009) menyebutkan bahwa penyuluhan, pelayanan dan pengaturan secara umum merupakan pilar utama pembangunan pertanian dan peternakan, secara khusus menjadi penentu keberhasilan usahatani petani peernak.

Rata-rata peningkatan penerapan peternak tentang teknis dan manajemen beternak sapi bali sangat rendah yakni 12,75 (15,45\%), peningkatan terjadi dari 82,54\% sebelum dilaksanakan FGD menjadi 95,29\% setelah dilaksanakan FGD. Nilai peningkatan masing-masing indikator penerapan teknis dan manajemen beternak sapi juga sangat rendah. Nilai tertinggi peningkatannya adalah perkandangan dan pengolahan limbah ternak 16,67 (21,19\%), disajikan pada Tabel 6.

Peningkatan penerapan peternak tentang teknis dan manajemen pemeliharaan sapi bali sangat rendah karena belum ada teknologi baru spesifik yang dianjurkan, sebagian besar teknologi masih yang lama, walaupun 
pengetahuannya tinggi, sikapnya bagus, tetapi penerapannya belum optimal.

Tabel 6. Penerapan Peternak Tentang Teknis Dan Manajemen Beternak Sapi Bali di Bali Sebelum dan Sesudah FGD

\begin{tabular}{|c|c|c|c|c|c|}
\hline \multirow{3}{*}{\multicolumn{2}{|c|}{$\begin{array}{l}\text { Indikator Teknis dan Manajemen } \\
\text { Beternak Sapi Bali }\end{array}$}} & \multicolumn{4}{|c|}{ Penerapan peternak } \\
\hline & & \multicolumn{2}{|c|}{ Sebelum Sesudah } & \multicolumn{2}{|c|}{ Peningkatan } \\
\hline & & FGD (\%) & FGD (\%) & Satuan & $(\%)$ \\
\hline 1 & $\begin{array}{l}\text { Pengetahuan penyuluhan } \\
\text { budidaya sapi }\end{array}$ & 86,67 & 95,33 & 8,67 & 10,00 \\
\hline 2 & $\begin{array}{l}\text { Perencanaan kelompok, jadwal } \\
\text { pertemuan }\end{array}$ & 82,67 & 95,00 & 12,33 & 14,92 \\
\hline 3 & Pemilihan bibit unggul sapi & 82,67 & 97,00 & 14,33 & 17,34 \\
\hline 4 & $\begin{array}{l}\text { Merencanakan beternak sapi } \\
\text { yang baik dan benar }\end{array}$ & 83,00 & 95,67 & 12,67 & 15,26 \\
\hline 5 & $\begin{array}{l}\text { Penyediaan pakan ternak yang } \\
\text { seimbang dan pengolahan pakan }\end{array}$ & 81,33 & 95,33 & 14,00 & 17,21 \\
\hline 6 & $\begin{array}{l}\text { Perkandangan dan pengolahan } \\
\text { limbah ternak }\end{array}$ & 78,67 & 95,33 & 16,67 & 21,19 \\
\hline 7 & $\begin{array}{l}\text { Deteksi birahi dan perkawinan } \\
\text { dengan IB }\end{array}$ & 84,67 & 93,33 & 8,67 & 10,24 \\
\hline \multirow[t]{3}{*}{8} & $\begin{array}{l}\text { Analisa Usaha dan pemasaran } \\
\text { hasil }\end{array}$ & 80,67 & 95,33 & 14,67 & 18,18 \\
\hline & Total & 660,33 & 762,33 & 102,00 & 124,34 \\
\hline & Rataan & 82,54 & 95,29 & 12,75 & 15,45 \\
\hline
\end{tabular}

Supriatna (1978) menyatakan bahwa pengetahuan seseorang tentang suatu inovasi serta sikapnya terhadap inovasi menentukan kesiapan seseorang untuk menerapkan inovasi tersebut. Inovasi lambat diterapkan oleh peternak bisa jadi karena peternak menganggap inovasi atau pesan yang disampaikan oleh penyuluh rumit untuk dilakukan.

Hasil analisis menunjukkan bahwa terjadi perubahan yang signifikan $(\mathrm{P}<0,05)$ pada perilaku peternak tentang teknis dan manajemen beternak sapi bali di Bali, antara sebelum dan sesudah dilaksanakan FGD.

\section{SIMPULAN}

Berdasarkan hasil penelitian dan pembahasan diatas, dapat disimpulkan bahwa teknik FGD dapat diterapkan dalam kegiatan penyuluhan sapi bali di Bali. Teknik penyuluhan FGD dapat meningkatkan pengetahuan, sikap dan penerapan penyuluh di Bali. Teknik penyuluhan FGD dapat meningkatkan pengetahuan, sikap dan penerapan peternak sapi bali di Bali

\section{UCAPAN TERIMA KASIH}

Penulis mengucapkan terimakasih kepada seluruh responden penelitian selama pengumpulan data di lapangan.

\section{DAFTAR PUSTAKA}

Hadi, S. 1988. Statistik II. Eresco Jakarta, Bandung.

Inggriati, N. W. T. 2014. Perilaku Peternak Sapi Bali Perbibitan dalam Sistem Penyuluhan di Bali (Disertasi). Program Pascasarjana Universitas Udayana. Denpasar .

Mosher AT. 1987. Menggerakan dan Membangun Pertanian. Yasaguna. Jakarta.

Faisal, S. 1999. Format-format Penelitian Sosial, dasr-dasar dan aplikasi. PT Raja Grafindo Persada Jakarta

Setyarini, D. 2009. Skripsi Pengaruh Intensitas Penyuluhan terhadap Tingkat Partisipasi Masyarakat dalam Program Penghijauan Kota : Studi Kasus Kecamatan Kota Kabupaten Wajo. Universitas Indonesia. Jakarta.

Singarimbun, M. dan S. Effendi. 1995. Metode Penelitian Survai. Edisi Kedua LP3ES, Jakarta.

Suparta, N., K. K. Nuraini., I. B Sutrisna., W. Inggriati., I. G Suartha., dan I. G. N Made. 2009. Penyuluhan Peternakan. Universitas Udayana, Denpasar.

Supriatna, 1978. Adopsi Teknologi Baru dikalangan petani. Agroekonomi, Departemen Pertanian. Fakultas Pertanian Universitas Gajah Mada, Yogyakarta

Walgito, B. 2003. Psikologi Sosial Suatu Pengantar, Andi Offset, Yogyakarta

Wiguna AA, NW Tatik Inggriati, I N Budiana dan I GM. Widianta. 2013. Peran Penyuluh dalam Mendukung Program Swasembada Daging Sapi Secara Berkelanjutan di Bali. Laporan Hasil Penelitian. Balai Pengkajian Teknologi Pertanian Bali. 